\title{
Occupational Exposure to Blood and Body Fluids Among Nurses in Public Hospitals of the Emergency Department and Intensive Care Unit, Addis Ababa, Ethiopia: Cross-sectional Study
}

Ousman Adal ( $\sim$ adalousman5@gmail.com )

Bahir Dar University

Asmamaw Abebe

Bahir Dar University

\section{Research Article}

Keywords: Occupational exposure, blood and body fluids, emergency, intensive care unit, Ethiopia

Posted Date: January 24th, 2022

DOI: https://doi.org/10.21203/rs.3.rs-1272527/v1

License: (c) (1) This work is licensed under a Creative Commons Attribution 4.0 International License. Read Full License 


\section{Abstract}

Background: Exposure to blood and body fluids causes major health hazards and serious concerns among health care professionals in their work settings. The prevalence of exposure to blood and body fluids is increasing, particularly for nurses who work in the emergency unit. The study aimed to assess the prevalence of occupational exposure to blood and body fluids, and its associated factors among nurses in public hospitals in the emergency department and intensive care unit, in Addis Ababa, Ethiopia.

Methods: A cross-sectional study was conducted from March 18, 2021, to April 20, 2021. Simple random sampling was used to select the studies in public hospitals. Semi-structured self-administer questioners were used to collect the data and analysis using SPSS version 25. Logistic regression model was used to identify the factors associated with exposure to blood and body fluids.

Results: About 198 (0.76 with 95\% Cl: $0.71,0.81)$ had been exposed to blood and body fluids in their professional lifetime, and $167(0.64$ with $95 \% \mathrm{Cl}: 0.58,0.70)$ were exposed to blood and body fluids in the last 12 months. Being male ( $\mathrm{AOR}=2.88,95 \% \mathrm{Cl}: 1.35,6.12)$, a lack of access to handwashing facilities $(A O R=5.02,95 \% \mathrm{Cl}: 3.73,14.51)$, not wearing a face shield and apron $(A O R=6.21,95 \% \mathrm{Cl}: 2.39,9.55)$, and a lack of personal protective equipment $(A O R=5.53,95 \% \mathrm{Cl}: 1.87,10.38)$ were all found to be significantly associated with exposure to blood and body fluids.

Conclusion: As a result of the lack of personal protective equipment, the majority of nurses did not consistently wear an apron and face shield while providing patient care, putting them at a higher risk of acquiring blood-borne pathogens.

\section{Introduction}

In every clinical setting, health care professionals often face numerous occupational hazards, such as exposures to human blood and body fluids (BBFs), because of working at health facilities whose activities involve direct contact with their patients (1).

Nurses, as the staff group, particularly in the emergency department (ED) and intensive care unit (ICU), are always in contact with their patients to provide immediate care. It is also overcrowded and tied-down work, so they are at the highest risk of such exposure $(1,2)$.

Recent research shows that exposure to BBFs is mostly caused by needle stick injuries (42.6\%), and developing countries such as, Ethiopia, Nigeria, Tanzania, Kenia and Tunisia account for over $90 \%$ of these events (2). This preventable exposure affects approximately 1000 infections a year with exposure to 20 different blood-borne pathogens (3).

The consequences of exposure to BBFs comprise the transmission of various types of pathogens like hepatitis B virus (HBV), hepatitis C virus (HCV), human immune deficiency virus (HIV), and other bloodborne pathogens that result in systemic and localized site infection $(4,5)$. Furthermore, nerve damage 
from a needle stick may occur, as well as the possibility of the needle breaking off into the skin. Additionally, significant anxiety and depression may occur following an event related to fear of infection (6).

Exposure to blood and body fluids is a serious concern among health care professionals in their work settings. The prevalence is increasing, particularly for nurses in the emergency unit (7-9). For example, a study conducted in the United States of America (USA) revealed that the prevalence of exposure to BBFs among nurses was (31.3\%) (10). In a similar study done in Iran among health care workers (HCWs), the highest rates of exposure were among nurses with less than 3 years of experience $(74.6 \%)$ who were young and recently employed. Of those nurses, $3 \%$ of them had got an infection from known HIV positive, $13 \%$ of nurses were known hepatitis B serum antigen (HBs Ag-positive) and $2 \%$ were HCV positive patients, but the study was not specific to nurses, and nurses in ICU were excluded (11).

The frequency and an annual rate of exposure to BBFs among nurses are higher in the emergency department. For instance, according to the research conducted by Gourni $\mathrm{P}$ et al. reported that $(39.5 \%)$ and $27 \%$ of nurses were exposed to BBFs respectively (7) but, the study didn't include nurses working in ICU. Based on the above study, $2.9 \%$ of nurses had obtained diseases related to their exposure $(7,12)$.

A systematic review and meta-analysis conducted in 2017 from 21 African countries disclosed that from $65.5 \%$ of HCWs were exposed to BBFs, and nurses accounted for (67.2\%) (13). Overcrowding, a lower ratio of HCWs to patients, limited awareness of the risks associated with exposure to BBFs, failure to implement standard precautions, inadequate supplies of basic safety equipment, lack of training, and inadequate supply of PPE are factors that increase the burden $(13,14)$.

Currently, in Ethiopia, a lack of reports exists to quantify the pooled prevalence of exposures to BBFs among health care workers (HCWs). Moreover, the epidemiology of blood-borne infections in Ethiopia has been on the rise and dynamically changing over the past decades, along with poor compliance with standard precautions among HCWs (15).

There is a limitation of a study conducted on occupational exposure to BBFs among nurses rather than the study available on overall HCWs in Ethiopia. And also, there is no published study yet, particularly at the ED and ICU regarding occupational exposure to BBFs. Therefore, this study was aimed at determining occupational exposure to BBFs and its associated factors among nurses in Addis Ababa city in the public hospitals of the ED and ICU. This study also serves to provide new knowledge regarding occupational exposure to BBFs among nurses in emergency departments and intensive care units.

\section{Methods}

\section{Study design and area}

A cross-sectional study was conducted among nurses in public hospitals in Addis Ababa city in the emergency department and intensive care unit from March 18, 2021, to April 20, 2021. Addis Ababa is the 
capital city of Ethiopia, which is located in the central part of Ethiopia. Also, it is the seat of the African Union and the United Nation's World Economic Commission for Africa. In Addis Ababa city, there are more than 53 hospitals, thirteen (13) are public hospitals and more than 40 are private hospitals (16). The study population contains all nurses who were working in five randomly selected public hospitals in Addis Ababa city in the ED and ICU. The lottery method of simple random sampling technique was used to select five public hospitals from thirteen public hospitals. All nurses in randomly selected public hospitals who were involved in patient care in the ED and ICU were enrolled in this study.

\section{Sample size, sampling procedure and technique}

The actual sample size for the study was determined using a single population proportion formula $\{\mathrm{n}$ $\left.=\left[(z a / 2)^{2} p(1-p)\right] / d^{2}\right\}, n=$ sample size, $z a / 2=95 \%$ confidence level, $P=$ the proportion of exposure to BBFs in the previous study (41.2\%) (17), $d=$ margin of error $(0.05)$. By considering $10 \%$ of non-response rate, the final sample size of the study was 266 . The lottery method of simple random sampling technique was used to select five public hospitals. The sample size for each hospital was proportionally allocated based on the number of nurses in each ED and ICU. Individuals who fulfilled the inclusion criteria were selected using systematic random sampling at two intervals from their list.

\section{Data collection tools}

The English version of the self-administer questionnaire was used to collect the data. The tools were divided into four sections: participant sociodemographic (7 items), participant behavioral characteristics (5 items), institutional factors ( 4 items), and exposure to blood and body fluids ( 12 items) obtained from a modified version of the study conducted at Tikur Anbessa specialized hospital (17).

\section{Data quality control}

Training was given to data collectors, and appropriate supervision was done. A pre-test was conducted two weeks before actual data collection using $5 \%$ of the sample size. The internal consistency of instruments in the pretest data (questioners) was reliable (Cronbach's alpha $=0.766$ ). After the pretest, some explanations were modified, re-edited, and arranged. The collected data was checked for completeness and some of unclear statements were corrected.

\section{Data processing and analysis}

Data was cleaned up, checked the completeness of questioners, and given code, and entered into EPIData version v4.6.0.4. Then it was exported to SPSS version 25 for further analysis. The result was presented in narration, graphs, and tabulations. Binary logistic regression analysis model was used to identify factors that determine exposure to BBFs. The model fitness of the variable was tested using 
Hosmer's and Lemons show test. All independent variables with a p-value of $<0.25$ from bivariate logistic regression analysis were fitted into a multivariable logistic regression analysis to control the possible effect of confounders. Finally, the variables which were independently associated with exposure to BBFs were identified on $\mathrm{OR}$, with $95 \% \mathrm{Cl}$ and $\mathrm{p}$-value $<0.05$.

\section{Results}

Sociodemographic characteristics of study participants (Table1)

Table 1: Sociodemographic characteristics of study participants, June 2021. 


\begin{tabular}{|c|c|}
\hline Variables & No $(\%), N=260$ \\
\hline \multicolumn{2}{|l|}{ Sex } \\
\hline Male & $121(46.5)$ \\
\hline Female & $139(53.5)$ \\
\hline \multicolumn{2}{|l|}{ Age } \\
\hline $20-29$ & $164(63.1)$ \\
\hline $30-39$ & $88(33.8)$ \\
\hline $40-49$ & $8(3.1)$ \\
\hline \multicolumn{2}{|l|}{ Educational status } \\
\hline Diploma & $26(10.0)$ \\
\hline BSc degree & $216(83.1)$ \\
\hline MSc degree & $18(6.9)$ \\
\hline \multicolumn{2}{|l|}{ Work experience } \\
\hline $1-9$ years & $189(72.7)$ \\
\hline 10-19 years & $70(26.9)$ \\
\hline $20-29$ years & $1(0.4)$ \\
\hline \multicolumn{2}{|l|}{ Working institution } \\
\hline Tikur Anbessa specialized hospital & $66(25.4)$ \\
\hline St. Paulo's specialized hospital & $105(40.4)$ \\
\hline Alert specialized hospital & $28(10.8)$ \\
\hline Yekatit 12 hospital & $28(10.8)$ \\
\hline Zewditu memorial hospital & $33(12.6)$ \\
\hline \multicolumn{2}{|l|}{ Working unit } \\
\hline Emergency & $169(65)$ \\
\hline ICU & $91(35)$ \\
\hline
\end{tabular}

'A total of 260 nurses participated in the study, which had a response rate of $97.7 \%$. The majority (53.5\%) of nurses who participated in this study were females, and (63.1\%) of participants were aged in the range between 20-29 years with a mean age of $29.68 \pm 4.37$. The majority $(83.1 \%)$ of study participants had a BSc degree 
Behavioral characteristics of study participants (Table2)

The majority of respondents (88.5\%) had used a glove, gown, and face mask consistently during patient care.

Table 2: Behavioral characteristics of study participants, June 2021, $(n=260)$

\begin{tabular}{|c|c|}
\hline Variables & Frequency (\%) \\
\hline \multicolumn{2}{|c|}{ Did you use a glove, gown, and face mask consistently during patient care? } \\
\hline Yes & $230(88.5)$ \\
\hline No & $30(11.5)$ \\
\hline \multicolumn{2}{|c|}{ Did you use a face shield and apron consistently during the procedure? } \\
\hline Yes & $74(28.5)$ \\
\hline No & $186(71.5)$ \\
\hline \multicolumn{2}{|c|}{ Did you have chewed khat? } \\
\hline Yes & $66(25.4)$ \\
\hline No & $194(74.6)$ \\
\hline \multicolumn{2}{|c|}{ Did you have drank alcohol } \\
\hline Yes & $61(23.5)$ \\
\hline No & $199(76.5)$ \\
\hline \multicolumn{2}{|c|}{ Are you concerned about exposure to BBFs and the impact of its outcome? } \\
\hline Yes & $218(83.8)$ \\
\hline No & 1. $42(16.2)$ \\
\hline
\end{tabular}

Institutional factors of occupational exposure to blood and body fluids (Table3)

More than half, (66.5\%) of study participants were fully vaccinated against HBV as a professional. Approximately (67.7\%) of respondents said that there was not enough PPE available throughout the year.

Table 3: Institutional factors of occupational exposure to blood and body fluids, June 2021. 


\begin{tabular}{|c|c|}
\hline Variables & Frequency (\%), N = 260 \\
\hline \multicolumn{2}{|c|}{ Have you ever took HBV as a professional? } \\
\hline Yes & $173(66.5)$ \\
\hline No & $87(33.5)$ \\
\hline \multicolumn{2}{|c|}{ Have you ever received training on infection prevention? } \\
\hline Yes & $159(61.2)$ \\
\hline No & $101(38.8)$ \\
\hline \multicolumn{2}{|c|}{ Does PPE available throughout the year in your hospital? } \\
\hline Yes & $84(32.3)$ \\
\hline No & $176(67.7)$ \\
\hline \multicolumn{2}{|c|}{ Are there enough hand washing facilities in the department? } \\
\hline Yes & $107(41.2)$ \\
\hline No & $153(58.8)$ \\
\hline
\end{tabular}

Prevalence of occupational exposure to blood and body fluids among nurses (Table4)

Almost (76.2\%) nurses were exposed to BBFs in their professional lives. Of those, nearly (64.2\%) were exposed to BBFs in the last 12 months. Among $(76.2 \%)$ of the exposed nurses, the majority $(79.8 \%)$ of them were exposed more than once a year. About (73.2\%) of the study participants identified the status of the source patients, and from those tested, nearly $(19.3 \%),(8.2 \%)$, and $(6.9 \%)$ of them were positive for $\mathrm{HIV}, \mathrm{HBV}$, and HCV respectively.

Table 4: Occupational exposure to blood and body fluids among nurses, June 2021. 


\begin{tabular}{|c|c|}
\hline Variables & Frequency (\%), $\mathrm{n}=198$ \\
\hline \multicolumn{2}{|l|}{ Frequency of exposure per year } \\
\hline One time & $40(20.2)$ \\
\hline More than one & $158(79.8)$ \\
\hline Exposure to BBFs at the emergency department & $130(78)$ \\
\hline Resuscitation & $65(50)$ \\
\hline Triage & $21(16)$ \\
\hline Procedure & $8(6)$ \\
\hline Both procedure and resuscitation & $36(28)$ \\
\hline Exposure to BBFs at ICU & $68(73)$ \\
\hline \multicolumn{2}{|l|}{ Parts of the body exposed to BBFs } \\
\hline Hands & $89(44.9)$ \\
\hline Eye splash & $36(18.2)$ \\
\hline Legs & $17(8.6)$ \\
\hline Both hand and eye splash & $56(28.3)$ \\
\hline \multicolumn{2}{|l|}{ Type of procedure leading exposure to BBFs } \\
\hline Needle disposal & $27(13.6)$ \\
\hline IV setup & $60(30.3)$ \\
\hline Blood collection & $39(19.7)$ \\
\hline Both blood collection and IV setup & $67(33.8)$ \\
\hline Bed bath and other procedure & $5(2.6)$ \\
\hline \multicolumn{2}{|l|}{ Did you follow the status of the source patients? } \\
\hline Yes & $145(73.8)$ \\
\hline No & $53(26.2)$ \\
\hline \multicolumn{2}{|l|}{ Sero-status of the source patients } \\
\hline HIV +VE & 28 (19.3) \\
\hline HBV +VE & $12(8.2)$ \\
\hline $\mathrm{HCV}+\mathrm{VE}$ & $10(6.9)$ \\
\hline Negative & $95(65.5)$ \\
\hline
\end{tabular}


Did you take prophylaxis if the source patient was sero +VE?

\begin{tabular}{|cc|}
\hline Yes & $42(84)$ \\
\hline No & $8(16)$ \\
\hline Did you complete the prophylaxis? & \\
\hline Yes & $41(97.6)$ \\
\hline No & $1(2.4)$ \\
\hline
\end{tabular}

Factors associated with occupational exposure to blood and body fluids (Table5)

The model fitness of the variable using the Hosmer and Lemeshow test showed that the dependent variable was $99.6 \%$ explained by the independent variables. In multivariable logistic regression analysis, gender, wearing of face shield and apron, accessibility of handwashing facilities, and availability of PPE in their hospital were found to be significantly associated with occupational exposure to BBFs at $p$-value $<0.05$. Males had 2.8 times the odds of being exposed to BBFs than females (AOR $=2.88,95 \% \mathrm{Cl}: 1.35$, 6.12). Nurses who complained about the lack of handwashing facilities in their hospital had 5 times more odds of exposure to BBFs compared to those who had not complained (AOR $=5.02,95 \%$ Cl: $3.73,14.51$ ). Nurses who did not consistently wear face shields and an apron during the procedure had a 6 times higher risk of BBF exposure than those who did (AOR $=6.21,95 \% \mathrm{Cl}: 2.39,9.55)$. Nurses who reported the lack of PPE in their hospital had 5.5 times higher odds of exposure to BBFs compared to those who reported that PPE was available in their hospital throughout the year ( $\mathrm{AOR}=5.53,95 \% \mathrm{Cl}: 1.87,10.38)$.

Table 5: Factors associated with occupational exposure to blood and body fluids, June 2021. 


\begin{tabular}{|c|c|c|c|c|}
\hline & \multicolumn{4}{|c|}{$\begin{array}{l}\text { Occupational exposure } \\
\text { to blood and body fluids }\end{array}$} \\
\hline Variables & Yes & No & COR $(95 \% \mathrm{Cl})$ & AOR (95\%Cl) \\
\hline \multicolumn{5}{|l|}{ Sex } \\
\hline Male & 102 & 19 & $2.40(1.31,4.41)^{\star}$ & $2.88(1.35,6.12)^{\star}$ \\
\hline Female & 96 & 43 & 1.00 & 1.00 \\
\hline \multicolumn{5}{|c|}{ Educational status } \\
\hline Diploma & 17 & 9 & $0.23(0.04,1.26)$ & $0.53(0.06,4.05)$ \\
\hline BSc degree & 165 & 51 & $0.40(0.09,1.81)$ & $0.57(0.09,3.51)$ \\
\hline MSc degree & 16 & 2 & 1.00 & 1.00 \\
\hline \multicolumn{5}{|c|}{ Experience at ED/ICU } \\
\hline $1-9$ years & 176 & 59 & $0.40(0.12,1.40)$ & $0.72(0.17,3.11)$ \\
\hline $10-19$ years & 22 & 3 & 1.00 & 1.00 \\
\hline \multicolumn{5}{|c|}{ Using shield and apron } \\
\hline Yes & 38 & 36 & 1.00 & 1.00 \\
\hline No & 160 & 26 & $5.83(3.15,10.79)^{\star \star}$ & $6.21(2.39,9.55) * \star$ \\
\hline \multicolumn{5}{|c|}{ Concerned exposure to BBF } \\
\hline Yes & 163 & 55 & 1.00 & 1.00 \\
\hline No & 35 & 7 & $1.68(0.70,4.02)$ & $1.63(0.53,4.96)$ \\
\hline \multicolumn{5}{|c|}{ Vaccinated to HBV } \\
\hline Yes & 136 & 37 & 1.00 & 1.00 \\
\hline No & 62 & 25 & $0.67(0.37,1.21)$ & $0.62(0.29,1.36)$ \\
\hline \multicolumn{5}{|l|}{ Availability of PPE } \\
\hline Yes & 36 & 48 & 1.00 & 1.00 \\
\hline No & 162 & 14 & $15.42(7.69,24.95)^{\star \star}$ & $5.53(1.87,10.38)^{\star \star}$ \\
\hline \multicolumn{5}{|c|}{ Hand washing facility } \\
\hline Yes & 54 & 53 & 1.00 & 1.00 \\
\hline No & 144 & 9 & $15.70(7.25,34.00)^{\star \star}$ & $5.02(3.73,14.51)^{\star \star}$ \\
\hline
\end{tabular}

Note. 1:00: reference, *Significant at $p$-value $<0.05,{ }^{*}$ significant at $p$-value $<0.005$ 
COR: crude odd ratio, AOR: adjusted odd ratio

\section{Discussion}

Occupational exposure to blood and body fluids among nurses during patient care leads to the transmission of different blood-borne pathogens, which is impacting their health and health care service for patients. In particular, developing countries such as Ethiopia can exacerbate the problem due to a lack of PPE, a low nurse-to-patient ratio, poor infrastructure, fragmentary hygienic service, overcrowding of patients, and inconsistent use of PPE (18).

In this study, the prevalence of exposure to BBFs among nurses in the emergency department and ICU was $(0.76$ with $95 \% \mathrm{Cl}: 0.71,0.81)$ in their professional lifetime, and nearly $(0.64$ with $95 \% \mathrm{Cl}: 0.58,0.70)$ exposed to BBFs in the last 12 months. This implies that a higher proportion of nurses are exposed to BBFs at the ED and ICU. The one-year exposure to BBFs is comparable with the study that was reported from India (68.64\%), Tanzania (63\%), Nigeria (68\%), Gondar town (65.3\%), and Mizan Tepi University $(65.3 \%)(4,14,19-21)$. However, the result is much higher than the study conducted in Turkey $(13.7 \%)$, Iran (34.7\%), Australia (48.1\%), South Africa (21.9\%), Kenia (22\%), Tunisia (25.6\%), Haramaya University (36.1\%), Debre Berhan University (32.8\%), and Arada sub-city health center, Addis Ababa (40\%) (22-30). This discrepancy may be due to variation in the study participants, lack of PPE, a higher load of patients, and infrequent use of PPE among participants in this study setting. For instance, in this study, participants were only nurses working in the ED and ICU, which is over-crowded, and infrequent lack of PPE was frequently observed, although in the above-mentioned study were conducted at all departments in the study hospitals on all HCWs (22-30).

The findings of this study showed that $79.8 \%$ of nurses were exposed to BBFs more than once per year, which is a greater variation to a study done at Jimma University (38.5\%) (31). The variation could be a result of the inadequacy of PPE, and infrequent use of it by nurses in this study setting (23). The study also revealed that blood/body fluid splash (46\%) was the most common way of exposure. This is consistent with the findings of a study conducted in Turkey (40.6\%) (28), but differs from findings in Iran (92.8\%), Australia (57\%), Nigeria (38.4\%), Tanzania (71\%), Haramaya University (26.5\%), and Jimma University $(78.8 \%)$, in which NSI was the most common mode of exposure $(14,21,22,24,30,31)$. The discrepancy might be due to variation in the study period, population, and setting, for instance, this study was conducted in five public hospitals and particularly on nurses at the ED and ICU, whereas a study in Haramaya was conducted in only one institution on all health care workers, including all working units $(22,31)$.

The finding showed that exposure to blood and body fluids mostly happens on hands (44.9\%). This is supported by a study published by Tanzania and Haramaya University, which found that exposure to BBFs on hands accounted for $85.5 \%$ and $86.6 \%$, respectively, but the proportion is higher $(14,22)$. In this study, $96 \%$ of nurses took action immediately after exposure through both washing the exposed site and reporting to the respective person. This is agreed with the study conducted in India (100\%), Tunisia 
(92.8\%), and Tanzania $(91 \%)(14,19,25)$. About $(73.8 \%)$ of nurses have identified the status of the source patients and from those tested patients nearly $19.3 \%, 8.2 \%$, and $6.9 \%$ of them were positive for HIV, HBV, and $\mathrm{HCV}$ respectively, which indicated that nurses are threatened by the transmission of blood-borne pathogens commonly for HIV, HBV, and HCV. Moreover, the findings of this study showed that the risk of transmission of blood borne pathogens among nurses exposed to BBFs is higher than the study done in Tunisia (25), which was $(1.1 \%, 1.6 \%$, and $5.25 \%)$ of source patients were positive for HIV, HCV, and HBV respectively. The difference is explained by the fact that this study was conducted at the ED and ICU, which is twinge work, thus nurses are attributed to such exposure (13).

In this finding, the sex of respondents, accessibility of handwashing facilities, wearing of a face shield, and apron consistently during the procedure, and availability of PPE constantly throughout the year in their hospital were found to be factors associated with occupational exposure to blood and body fluids. Males had 2.8 times the odds of being exposed to BBFs than females. This is congruent with the studies reported in Turkey, South Africa, Kenia, and Jimma $(26-28,31)$ but contrary with the study in Tanzania (14). The possible explanation is that male nurses underestimated the facts, paying no attention to the burden and the consequence of exposure to blood and body fluids (32).

Nurses who complained about the lack of handwashing facilities in their hospital had 5 times more odds of exposure to BBFs compared to those who didn't complain. Nurses who didn't wear face shields and an apron consistently during the procedure had 6 times higher odds of exposure to BBFs. Nurses who reported, there was a lack of PPE in their hospital had 5.5 times higher odds of exposure to BBFs than those who reported that personal protective equipment was available in their hospital throughout the year. This is further supported by many studies, such as the studies in Tanzania, Wolaita Zone (southern Ethiopia), Awi Zone (Northwest Ethiopia), Gondar town, Bahir Dar town, and Arada health center (Addis Ababa, Ethiopia) $(4,6,14,23,33,34)$. The reason could be described as the availability of PPE in health care facilities influencing nurses' habits of using PPE during patient care and procedures, thereby reducing exposure to contaminated BBFs and its impact on the outcome of exposure. Furthermore, the infrequent availability of PPE reduced nurses' compliance to wear PPE such as a glove, face mask, face shield, and apron, potentially amplifying exposure to BBFs; and finally, increasing the transmission of blood borne pathogens. Giving patients care without PPE can also reduce nurses' concentration during activities, which can lead to anxiety and further exposure to blood and body fluids. $(15,18,20)$.

\section{Implications of the study}

This study will be used to provide information to health care providers, non-governmental organizations, and policymakers for appropriate planning and interventions regarding occupational BBFs, as well as its associated factors in nurses.

This study also serves as new knowledge regarding occupational exposure to blood and body fluids.

Moreover, the result of this study helps as baseline data for further longitudinal and action-based studies. 


\section{Strength and limitations}

As the strength, this study was conducted in five randomly selected public hospitals, thus it could be generalized to all nurses working in public hospitals in the emergency department and intensive care unit. This study shared the limitation of cross-sectional study design, hence it is difficult to determine the causal relationships between variables.

\section{Conclusion}

This study showed that a higher proportion of nurses at the emergency department and intensive care unit were exposed to blood and body fluids in the study area. Exposure to blood and body fluids was positively associated with a lack of personal protective equipment, inconsistent use of face shields and aprons, inaccessibility of handwashing facilities, and being male.

\section{Abbreviations}

\begin{tabular}{ll} 
AOR & Adjusted odd ratio \\
\hline BBFs & Blood and body fluids \\
\hline $\mathrm{Cl}$ & Confidence interval \\
\hline COR & Crude odd ratio \\
\hline ED & Emergency departments \\
\hline HCWs & Health care workers \\
\hline ICU & Intensive care unit \\
\hline PPE & Personal protective equipment
\end{tabular}

\section{Declarations}

\section{Authors' contribution}

Ousman Adal developed the proposal, analyzed the data, interpreted the results, and drafted the manuscript. Asmamaw Abebe revised the proposal, checked the data, and revised the manuscript.

Funding: No

\section{Availability of data and materials}

The data that supports the findings of this study is available upon reasonable request from the corresponding authors. 
This study was approved by ethical review board of the College of health sciences, Addis Ababa University. Written consent was obtained from each study participant. Confidentiality and privacy were maintained through the study period.

Consent for publication: Not applicable

\section{Computing interest}

The authors declare that they have no computing interest.

\section{Acknowledgements}

The authors are grateful to the data collectors, emergency and intensive care unit coordinators, and all study participants for their contributions to the study's success.

\section{References}

1. Jagger J, Powers RD, Day JS, Detmer DE, Blackwell B, Pearson RD. Epidemiology and prevention of blood and body fluid exposures among emergency department staff. Journal of Emergency Medicine. 2004;12(6):753-65.

2. Gebremariyam BS. Determinants of occupational exposure to blood and body fluids, healthcare workers' risk perceptions and standard precautionary practices: a hospital-based study in Addis Ababa, Ethiopia. Ethiopian Journal of Health Development. 2019;33(1).

3. control cd. blood and body fluid management. BC CDC. oct,2017;8(6):7.

4. Abere G, Yenealem DG, Wami SD. Occupational Exposure to Blood and Body Fluids among Health Care Workers in Gondar Town, Northwest Ethiopia: A Result from Cross-Sectional Study. Journal of Environmental and Public Health. 2020;2020:3640247.

5. Madiba TK, Nkambule NR, Kungoane T, Bhayat A. Knowledge and Practices Related to Hepatitis B Infection among Dental and Oral Hygiene Students at a University in Pretoria. J Int Soc Prev Community Dent. 2018;8(3):200-4.

6. Yenesew MA, Fekadu GA. Occupational exposure to blood and body fluids among health care professionals in Bahir Dar town, Northwest Ethiopia. Safety and health at work. 2014;5(1):17-22.

7. Gourni P, Polikandrioti M, Vasilopoulos G, Mpaltzi E, Gourni M. Occupational exposure to blood and body fluids of nurses at emergency department. Health science journal. 2012;6(1):60.

8. Green-McKenzie J, McCarthy RB, Shofer FS. Characterisation of occupational blood and body fluid exposures beyond the Needlestick Safety and Prevention Act. J Infect Prev. 2016;17(5):226-32.

9. Marković-Denić L, Oštrić I, Pavlović A, Kalimanovska-Oštrić D. Knowledge and occupational exposure to blood and body fluids among health care workers and medical students. Acta chirurgica iugoslavica. 2012;59(1):71-5. 
10. Dement JM, Epling C, Østbye T, Pompeii LA, Hunt DL. Blood and body fluid exposure risks among health care workers: results from the Duke Health and Safety Surveillance System. American journal of industrial medicine. 2004;46(6):637-48.

11. Naderi H, Sheybani F, Bojdi A, Mostafavi I, Khosravi N. Occupational exposure to blood and other body fluids among health care workers at a university hospital in Iran. Workplace health \& safety. 2012;60(10):419-22.

12. Merchant RC, Becker BM, Mayer KH, Fuerch J, Schreck B. Emergency department blood or body fluid exposure evaluations and HIV postexposure prophylaxis usage. Academic emergency medicine. 2003;10(12):1345-53.

13. Auta A, Adewuyi EO, Tor-Anyiin A, Aziz D, Ogbole E, Ogbonna BO, et al. Health-care workers' occupational exposures to body fluids in 21 countries in Africa: systematic review and metaanalysis. Bulletin of the World Health Organization. 2017;95(12):831.

14. Chalya PL, Seni J, Mushi MF, Mirambo MM, Jaka H, Rambau PF, et al. Needle-stick injuries and splash exposures among health-care workers at a tertiary care hospital in north-western Tanzania. Tanzania Journal of Health Research. 2015;17(2).

15. Sahiledengle B, Tekalegn Y, Woldeyohannes D, Quisido BJE. Occupational exposures to blood and body fluids among healthcare workers in Ethiopia: a systematic review and meta-analysis. Environ Health Prev Med. 2020;25(1):58.

16. Sahile AT. level-of-nurses-job-satisfaction-and-associated-factors-working-in-public-hospitals-ofaddis-ababa-ethiopia. Department of Public Health, Universal Medical College, Addis Ababa, Ethiopia: Addis Ababa University, Addis Ababa, Ethiopia, November 18, 2019.

17. Atlaw WD. Patterns of occupational exposure to patients' body fluids among health care workers in Tikuranbesa University Hospital, Addis Ababa, Ethiopia 2013.

18. Yasin J, Fisseha R, Mekonnen F, Yirdaw K. Occupational exposure to blood and body fluids and associated factors among health care workers at the University of Gondar Hospital, Northwest Ethiopia. Environmental Health and Preventive Medicine. 2019;24(1):18.

19. Islahi S, Mittal V, Sen M. Prevalence of needle-stick injuries among health-care workers in a tertiary care centre in North India. 2018.

20. Mekonnin T, Tsegaye A, Berihun A, Kassachew H, Sileshi A. Occupational exposure to blood and body fluids among health care workers in mizan Tepi university teaching hospital, bench maji zone, south west Ethiopia. Medical Safety \& Global Health. 2018;7(2):2574-0407.

21. Nmadu AG, Sabitu K, Joshua IA. Occupational exposure to blood and body fluids among primary health-care workers in Kaduna State, Nigeria. Journal of Medicine in the Tropics. 2016;18(2):79.

22. Alemayehu T, Worku A, Assefa N. Sharp injury and exposure to blood and body fluids among health care workers in health care centers of eastern Ethiopia. The international journal of occupational and environmental medicine. 2016;7(3):172.

23. Amerga E, Mekonnen T. Occupational exposure to blood and body fluids among health care workers in arada sub-city health centers of Addis Ababa, Ethiopia. Occupational Medicine \& Health Affairs. 
2018;6(4):2.

24. Bi P, Tully P, Pearce S, Hiller J. Occupational blood and body fluid exposure in an Australian teaching hospital. Epidemiology \& Infection. 2006;134(3):465-71.

25. Darouiche MH, Chaabouni T, Hammami KJ, Akrout FM, Abdennadher M, Hammami A, et al. Occupational blood exposure among health care personnel and hospital Trainees. Int J Occup Environ Med (The IJOEM). 2014;5(1 January):321-57-61.

26. Mbah CC. Reporting of accidental occupational exposures to blood and body fluids by doctors and nurses in the public primary health care setting of sub district $F$ of Johannesburg Metropolitan district 2014.

27. Mbaisi EM, Wanzala P, Omolo J. Prevalence and factors associated with percutaneous injuries and splash exposures among health-care workers in a provincial hospital, Kenya, 2010. Pan African Medical Journal. 2013;14(1).

28. Serinken M, Karcioglu O, Kutlu SS, Sener S, Keysan MK. A survey of needlesticks and sharp instrument injuries in emergency health care in Turkey. Journal of Emergency Nursing. 2009;35(3):205-10.

29. Sharew NT, Mulu GB, Habtewold TD, Gizachew KD. Occupational exposure to sharps injury among healthcare providers in Ethiopia regional hospitals. Annals of occupational and environmental medicine. 2017;29(1):7.

30. Tabatabaei SM, Pour FB, Avval JO, Osmani S, Mokhtari S, Bekheyr MA. Occupational exposure to blood and other body fluids among healthcare workers in three teaching hospitals, Southeast Iran. International Journal of Infection. 2016;3(3):e32879.

31. Belachew YB, Lema TB, Germossa GN, Adinew YM. Blood/body fluid exposure and needle stick/sharp injury among nurses working in public hospitals; Southwest Ethiopia. Frontiers in public health. 2017;5:299.

32. Asmr Y, Beza L, Engida H, Bekelcho T, Tsegaye N, Aschale Y. Assessment of Knowledge and Practices of Standard Precaution against Blood Borne Pathogens among Doctors and Nurses at Adult Emergency Room in Addis Ababa, Ethiopia. Emerg Med Int. 2019;2019:2926415.

33. Dilie A, Amare D, Gualu T. Occupational exposure to needle stick and sharp injuries and associated factors among health care workers in Awi Zone, Amhara Regional State, Northwest Ethiopia, 2016. Journal of Environmental and Public Health. 2017;2017.

34. Tadesse M, Meskele M, Tadesse A. Occupational exposure to blood and body fluids among health care workers in wolaita zone, southern Ethiopia. Developing Countries Studies. 2016;6(7):70-7. 